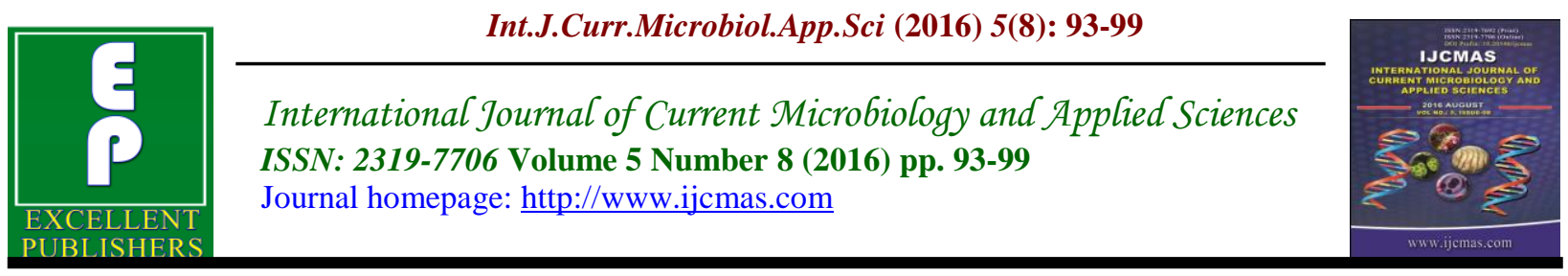

Original Research Article

http://dx.doi.org/10.20546/ijcmas.2016.508.012

\title{
Post Operative Enterococcus Infection from Cancer Patients in a Regional Cancer Centre, South India
}

\author{
B.G. Sumathi*, Mohd.Shaffiulla and Kumarswamy \\ 437,12th Cross, Sadashivanagar, Bangalore 560 080, India \\ *Corresponding author
}

\section{A B S T R A C T}

Keywords

Enterococci,

Immuno-

compromised,

Post operative

infections.

\section{Article Info}

\section{Accepted:}

09 July 2016

Available Online:

10 August 2016
A two year retrospective study was done to know the types of enterococcal species isolation, presence of multiply drug resistant enterococci and vancomycin resistant enterococci from post operative wounds of cancer patients in a regional cancer hospital, Kidwai Memorial Institute of Oncology, Bangalore. The study was done for the first time in our hospital in cancer patients. A retrospective study was done on post operative infected wound discharges and post operative drains in-situ discharges from surgery, gynaecology, head and neck and oral oncology departments in the department of microbiology at our regional cancer hospital in South India. Samples were analysed between January 2012 to December 2014. Bacterial isolation from the clinical samples were done by conventional laboratory methods in the department of microbiology. Antimicrobial susceptibility and resistance pattern to isolated pathogens were performed and interpreted as per NCCLS guidelines. Tests for vancomycin resistant enterococci and detection for beta-lactamase production was done accordingly. Only monomicrobial enterococcal post operative and drain discharges isolates were taken for study. A total number of three hundred and twenty two pus and wound discharge samples which came from the oncology departments of surgery, gynaecology, head and neck and oral were analysed. Enterococci species isolated were Enterococcus faecalis (E.faecalis)168 (52.17\%), Enterococcus faecium (E.faecium)150 (46.58\%) and Enterococci casseliflavus (E.casseliflavus) 4(1.24\%). Amongst the antibiotics all isolates were susceptible to the gycopeptides, vanomycin and teicoplanin. There was no beta-lactamase production from the isolates. The most common enterococcal species were Enterococcus faecalis, Enterococcus faecium and Enterococcus casseliflavus from post operative wound discharges. Post operative enterococcal infection may aggravate the morbidity and mortality of the cancer patients thereby prolonging hospital stay with an additional hospital cost and form one of the potential risk factors for health-care associated infection.

\section{Introduction}

Genus enterococci comprises gram-positive cocci that are catalase negative, usually facultative, anaerobic bacteria that grow in $6.5 \% \mathrm{NaCl}, 40 \%$ bile salts, and $0.1 \%$ methylene blue milk and at $\mathrm{pH}$ 9.6. They grow at 10 and $45^{\circ} \mathrm{C}$ and can resist $30 \mathrm{~min}$ at $60^{\circ} \mathrm{C}$ (Albert Manero, 1999; Ballows et al., 1991; Schleifer et al., 1984; Schleifer et 
al., 1987) and are the normal inhabitants of the gastrointestinal flora.

There are over 23 species of enterococci with clinical significance to date (Tyrrell et $a l ., 2002$ ) of which 2 species are particularly pathogenic to man; Enterococcus faecalis

(E.faecalis) causing 85-90\% of enterococci infections while Enterococcus faecium (E.faecium) causes 5-10\% (Lewis et al., 1990; Gordon et al., 1992; Patterson et al., 1995). Other Enterococcus species known to cause human infections include $E$. avium, $E$. gallinarium, E. casseliflavus, E. durans, E. raffinosus and $E$. mundtii. Infections from other enterococcal species are rare (Shankar et al., 2001; Dupre et al., 2003; Winn et al., 2006; Hoffmann et al., 1987).

Enterococci species have recently emerged as an important cause of serious nosocomial infection and to the spread of multi drug resistance among isolates (Murray, 1990). Multiply drug resistant enterococci are hardy pathogens which are known to spread drug resistance among hospital personnel and to patients and likewise treatment for serious enterococcal infections can be difficult.

The incidence of other species of enterococci from clinical sources shows an alarming increase with the properties of intrinsic resistance to several antibiotics including betalactams and glycopeptides (Dutka-Malen et al., 1995) Enterococci are intrinsically resistant to many antibiotics, including clindamycin, the penicillinaseresistant antistaphylococcal penicillins, and most cephalosporins (Murray et al., 1986). Acquired resistance to chloramphenicol, erythromycin, and tetracycline is relatively common. Studies have shown that enterococci highly resistant to aminoglycoside (Patterson et al., 1990) and are steadily increasing. Vancomycin resistance enterococci has also emerged, but it is uncommon at present (Courvalin et al., 1990; Facklam et al., 1999).

Enterococci infection various body sites to produce bacteremia, intra-abdominal infections, endocarditis, and urinary tract infections and primarily responsible to and the second most common gram positive pathogen for post operative infections (Shankar et al., 1999). The National Nosocomial Infections Surveillance System (USA) reported enterococci to be the second most common pathogen associated with nosocomial urinary tract infections.

Enterococci are primarily normal flora of the intestinal gut and due to break in the immune system and to predisposing risk factors like underlying malignancies and associated surgical risk factors infection ensue. Post operative enterococcal infection present as monomicrobial or polymicrobial infections where the pathogenic role of the enterococci presenting as poymicrobial infection with other pathogenic bacteria in sites of the urinary tract, wound and biliary tract may be difficult for interpretation. Accurate identification of enterococci to species level will enable us, to define the species-specific antimicrobial resistance characteristics, besides knowing the epidemiological pattern and their clinical significance in human infections.

\section{Materials and Methods}

A total of 322 post operative infected wound discharges and post operative drains in-situ discharges from oncology departments were analysed between 2011 to 2013. Bacterial isolation was done by conventional laboratory methods in the department of microbiology. The sources and species identification was done according of the devised scheme of Facklam and Collins (Facklam et al., 1989). 
Isolates were tested on the following media: heart infusion broths supplemented with mannitol, sorbitol, sorbose, arabinose, raffinose, lactose, and sucrose, pyruvate broth, bile esculin agar, brain heart infusion broth with $6.5 \% \mathrm{NaCl}$, motility medium, and trypticase soy agar and Moeller decarboxylase medium with arginine. The plates were incubated at $37^{\circ} \mathrm{C}$ for $48 \mathrm{hr}$. Isolates which produced acid from lactose, mannitol, and sorbitol, but not from arabinose or sorbose were identified as enterococcus faecalis. Isolates which produced acid from arabinose, lactose, and mannitol, but not from sorbitol or sorbose, were identified as E. faecium.

\section{Antimicrobial susceptibility testing}

Susceptibility and resistance pattern to isolated pathogens were done by the conventional Stokes' method of antibiotic testing and beta-lactamases was estimated by conventional method. The susceptibilities of all isolates to different antimicrobial agents were tested by the disc-agar method as standardised by the Clinical Laboratory Standards Institution (CLSI). The following antimicrobial discs and concentrations were used: ampicillin $(10 \mu \mathrm{g})$, vancomycin (30 $\mu \mathrm{g})$, teicoplanin $(30 \mu \mathrm{g})$, erythromycin (15 $\mu \mathrm{g})$, ciprofloxacin (5 $\mu \mathrm{g})$, amikacin (200 $\mu \mathrm{g})$, high level gentamicin $(120 \mu \mathrm{g})$, and linezolid (30 $\mu \mathrm{g})$ (Hi-media laboratory, Mumbai). The results were interpreted after $24 \mathrm{~h}$ of incubation at $35^{\circ} \mathrm{C}$. Quality control strains of E. faecalis (ATCC 51299) were used to ensure the potency of each antimicrobial agent tested.

\section{Beta-lactamases Detection}

Three hundred and twenty two samples were subjected for beta-lactamases by nitocefin disc method. All samples were negative for beta-lactamase production. Isolates were tested for 13-lactamase production by the rapid chromogenic-cephalosporin method (nitrocefin; Oxoid) Nitrocefin is the only reliable test for detecting beta-lactamase producing Enterococcus species.

\section{Results and Discussion}

Three hundred and twenty two enterococcal species were analysed which had E.faecalis 168 (52.17\%), E.faecium 150 (46.58\%) and E.casseliflavus $4(1.24 \%)$ as in Table 1 .

Amongst the antibiotics, all isolates were susceptible to the gycopeptides, vanomycin and teicoplanin. Resistance to erythromycin was highest to E.faecalis with 126 (75\%), Amikacin 118 (70.23\%), high level gentamicin $84(50 \%)$ but E.faecium had higher resistance to ampicillin 54 (36\%) than to E.faecalis or E.casseliflavus as shown in Table 2.

The maximum resistance was seen to the macrolide erythromycin for E.faecalis (75\%) followed by the aminogycoside amikacin $(70 \%)$ and to gentamicin was (50\%),ciprofloxacin(33.33\%), ampicillin $(26.19 \%)$ in our studies while E.faecium resistance pattern to erythromycin was 74.66\%), amikacin (68\%), high level gentamicin(46.66\%), ciprofloxacin(33.33\%) and to ampicillin was (36\%). None of the isolates were beta lactamase producer, and ampicillin resistance $\mathrm{w}$ as $(26.19 \%)$ and no glycopeptide resistant enterococci was encountered in our study particularly to vancomycin.

Table 3 illustrates the maximum post operative enterococcal infection was observed in the onco surgical department $76(53.52 \%)$ in the 51to70 years age limit while onco gynaecology depart had maximum infection 64(54.23\%) between the age limit of 31 to 51 years. Enterococcal infections from oncology departments of radiotherapy, oral and head and neck were 
less as illustrated in table 3 .

Enterococci were considered as commensal flora and less importance given when isolated from clinical specimens such as wound and urine. Now increasing reports have proved that this opportunistic bacterium can become pathogenic when it colonizes normal sites not uncommonly found with the potential to become invasive. Since the beginning of the $21^{\text {st }}$ century in the United States of America, enterococci have become major reservoir of antibioticresistant genes and vancomycin resistant enterococci a major cause of nosocomial infections especially of the bloodstream, urinary tract and surgical sites (Cetinkaya et al., 2000).

The commercially available system (VITEX-2, bioMérieux, France) in our laboratory identified E.faecalis and E.faecium correctly but could not identify other enterococcal species from the isolates. The conventional method of identifying
E.faecalis and E.faecium in our department was similar to the commercial system but the inter-species identification of other enterococci were not corroborating with the conventional method. We observed in our study the incidence and isolation of E.faecalis and E.faecium are similar to those of other authors (Facklam, 1972) whose majority of clinical isolates were E. faecalis, followed by E. faecium and study by Gordon et had similar findings.

Almost $98 \%$ of the enterococci were E.faecalis or E.faecium, comparable to the distribution of species found in recent studies of clinical isolates (Gullberg et al., 1989; Mackowiak, 1989; Maki et al., 1988).

There was no beta-lactamase production from our isolates which is similar to most studies. Post operative enterococi infections in immunocompromised or high risk cancer patients prolong the hospital stay and and form the one of the index factors for hospital infections.

Table.1

\begin{tabular}{|l|l|l|}
\hline \multicolumn{3}{|l|}{$\begin{array}{l}\text { Isolation of Enterococci species from Pus and Wound } \\
\text { discharges Total Number } \mathbf{3 2 2}\end{array}$} \\
\hline Sl.No. & Species & Number and Percentage \\
\hline 1. & E.faecalis & $168(52.17 \%)$ \\
\hline 2. & E.faecium & $150(46.58 \%)$ \\
\hline 3. & E.casseliflavus & $4(1.24 \%)$ \\
\hline
\end{tabular}

Table.2

\begin{tabular}{|c|c|c|c|c|}
\hline \multicolumn{5}{|c|}{ Resistance Pattern of Isolated Enterococci species } \\
\hline Sl.No. & Antibiotics & Faecalis (168) & Faecium (150) & Casseliflavus (4) \\
\hline 1. & Ampicillin & $44(26.19 \%)$ & $54 \quad(36 \%)$ & 0 \\
\hline 2. & Amikacin & $118(70.23 \%)$ & $102(68 \%)$ & 0 \\
\hline 3. & Ciprofloxacin & $56 \quad(33.33 \%)$ & $50 \quad(33.33 \%)$ & $1(25 \%)$ \\
\hline 4. & Erythromycin & $126(75 \%)$ & $112(74.66 \%)$ & $1(25 \%)$ \\
\hline 5. & Gentamicin & $84 \quad(50 \%)$ & $70 \quad(46.66 \%)$ & 0 \\
\hline 6. & Linezolid & $(2.38 \%)$ & $(1.33 \%)$ & 0 \\
\hline 7. & Teicoplanin & 0 & 0 & 0 \\
\hline 8. & Vancomycin & 0 & 0 & 0 \\
\hline
\end{tabular}


Table.3

\begin{tabular}{|c|c|c|c|c|c|}
\hline \multicolumn{6}{|c|}{$\begin{array}{l}\text { Isolation of Enterococci species from various oncology departments with age } \\
\text { wise distribution in Years }\end{array}$} \\
\hline \multicolumn{6}{|c|}{\begin{tabular}{l|l|ll|l} 
Sl. & Onco & No & Of & $0-30 y r s$ \\
No. & departments & Isolates & & \\
\end{tabular}} \\
\hline \multirow{2}{*}{\multicolumn{6}{|c|}{\begin{tabular}{|l|l|c|c|c|} 
Surgery & $142(44.09 \%)$ & $12(8.45 \%)$ & $54(38.02 \%)$ & $76(53.52 \%)$ \\
Gynaecology & $118(36.64 \%)$ & ----- & $64(54.23 \%)$ & $54(45.76 \%)$ \\
\end{tabular}}} \\
\hline & & & & & \\
\hline 3. & Radioth & $27(8.38 \%)$ & $4(14.81 \%)$ & $23(85.18 \%)$ & ----- \\
\hline 4. & Oral & $21(6.52 \%)$ & ------ & $9(42.85 \%)$ & $12(57.14 \%)$ \\
\hline 5. & $\begin{array}{l}\text { Head } \\
\text { Neck }\end{array}$ & $14(4.34 \%)$ & $4(28.57 \%)$ & $6(42.85 \%)$ & $4(28.57 \%)$ \\
\hline
\end{tabular}

Enterococcal strains isolated from cancer patients may show different sensitivity pattern from strains isolated from noncancerous patients. Macrolide resistance was higher to E.faecalis than to E.faecium and similarly resistance to amikacin, ciprofloxacin and to high-level gentamicin was seen more in E.faecalis than to E.faecium as reported by other studies but ampicillin resistance was seen more to E.faecium than to E.faecalis in our study.

No glycopeptide resistance was seen in our isolates a report similar to studies by Surgical risk factors as age, body mass index, presence of diabetes etc may have a role in polymicrobial post operative infections with more relevance given to cancer patients. However in our study we did not look into surgical risk factors. Studies on enterococcal isolation from post operative infected sites in cancer patients are not reported till date.

To conclude we observed maximum resistance to the macrolide, erythromycin towards the isolated E.faecalis amongst the enterococcal species and also as the predominant pathogen from the post operative infection sites. No multiply drug resistance was observed by E.faecalis, E. faecium or E.casseliflavus in the isolates. Vancomycin resistant enterococci was not encountered in our study. Appropriate treatment and control of enterococcal infections with current antimicrobial agents are becoming increasingly difficult due to diverse antimicrobial resistance mechanisms therefore antibiotic protocols need to be implemented for all cancer patients. Selective antibiotics necessary to post operative enterococcal isolates as reported in many studies will prevent hospital infections, minimize hospital stay and reduce the burden of the cost to the hospital. Post operative infection and associated risk factors is the need of the hour to minimize mortality and morbidity from the infection than the underlying immunocompromised status.

\section{References}

Acar, J.F., A.Y. Buu-Hoi. 1988. Resistance patterns of important Gram-positive pathogens. J. Antimicrob. Chemother., 21: 41-47.

Albert Manero, Anicet, R.B. 1999. Identification of Enterococcus spp. with a Biochemical Key. Appl. Environ. Microbiol., 65: 4425-4430.

Ballows, H.G., Trüper, M., Dwork in, W. Harder, K.H. Schleifer (ed.), Devriese, L.A., M.D. Collins, R. Wirth. 1991. The genus Enterococcus. In The 
prokaryotes. Springer-Verlag, New York, N.Y., 65: 1465-1477.

Cetinkaya, Y., Falk, P., Mayhall, C.G. 2000. Vancomycin-resistant enterococci. Clin. Microbiol. Rev.,13: 686-707.

Colman, G., L.C. Bail. 1984. Identification of streptococci in a medical laboratory. J. Apple. Bacteriol., 57: 12-14.

Courvalin, P. 1990. Resistance of enterococci to glycopeptides. Antimicrob. Agents Chemother., 34: 2291-2296.

Dupre, I., Zanetti, S., Schito, A.M., Fadda, G., Sechi, L.A. 2003. Incidence of virulence determinants in clinical Enterococcus faecium and Enterococcus faecalis isolates collected in Sardinia. J. Med. Microbiol., 52: 491-498.

Dutka-Malen, S., Evers, S., Courvalin, P. 1995. Detection of glycopeptides resistance genotypes and identification to the species level of clinically relevant enterococci by PCR. J. Clin. Microbiol., 33: 24-7.

Facklam, R.R. 1972. Recognition of group D streptococcal species of human origin by biochemical and physiological tests. Apple. Microbiol., 23: 1131-1139.

Facklam, R.R., M.D. Collins. 1989. Identification of Enterococcus species isolated from human infections by a conventional test scheme. J. Clin. Microbio., 27: 731-734.

Facklam, R.R., Sahm, D.F., Texeira, L.M. 1999. Enterococcus. In Manual of clinical microbiology 7th edition. Edited by: Murray PR, Baron EJ, Pfaller MA, Tenover FC, Yolken RH. ASM press, Washington, DC, 297305.

Fridkin, S.K., Gaynes, R.P. 1990. Antimicrobial resistance in intensive care units. Clin. Chest Med., 20: 30316.

Gordon, S., Swenson, J.M., Hill, B.C., Pigott, N.E., Facklam, R.R., Cooksey, R.C., Thornsberry, C., Jarvis, W.R., Tenover, F.C. 1992. Antimicrobial susceptibility patterns of common and unusual species of enterococci causing infections in the United States. Enterococcal Study Group. J. Clin. Microbiol., 30: 2373-8.

Gullberg, R.M., S.R. Homann, and J.P. Phair. 1989. Enterococcal bacteremia: analysis of 75 episodes. Rev. Infect. Dis., 2: 74-85.

Hoffmann, S.A., R.C. Moellering, Jr. 1987. The enterococcus: "putting the bug in our ears."Ann. Intern. Med., 106: 757761.

James, W.G., David, S., Stephen, J.P. 1991. Species Identification and Antibiotic Susceptibility Testing of Enterococci Isolated from Hospitalized Patients. Antimicrobial Agents Chemother., 5: 1943-1945.

Lewis, C.M., Zervos, M.J. 1990. Clinical manifestations of enterococcal infection. Eur. J. Clin. Microbiol. Infect. Dis., 9: 111-117.

Mackowiak, P.A.1989. The enterococci: evidence of species specific clinical and microbiologic heterogeneity. Am. J. Med.Sci., 296: 238-243.

Maki, D.G., W.A. Agger. 1988. Enterococcal bacteremia: clinical features, the risk of endocarditis, and management. Med., (Baltimore) 67: 248-269.

Methods for Antimicrobial Susceptibility Testing of Anaerobic Bacteria, 8th ed., M11-A8, 2012. Clinical Laboratory Standards Institute (CLSI - formerly NCCLS), Villanova, PA.

Morrison, A.J., R.P. Wenzel. 1986. Nosocomial urinary tract infections due to enterococcus: ten years' 
experience at a university hospital. Arch. Intern. Med., 146: 1549-1551.

Murray, B.E. 1990. The life and times of the enterococcus. Clin. Microbiol. Rev., 3: 46-65.

Murray, B.E., D.A. Church, A. Wanger, K. Zscheck, M. E.Levison, M.J. Ingerman, E. Abrutyn, and B. Mederski-Samoraj. 1986. Comparison of two P-lactamase-producing strains of Streptococcus faecalis. Antimicrob. Agents Chemother., 30: 861-864.

Parker, M.T., L.C. Bail. 1976. Streptococci and aerococci associated with systemic infection in man. J. Med. Microbiol., 9: 275-302.

Patterson, J.E., M.J. Zervos. 1990. Highlevel gentamicin resistance in Enterococcus: microbiology, genetic basis and epidemiology. Rev. Infect. Dis., 12: 644-652.

Patterson, J.E., Sweeney, A.H., Simms, M., Carley, N., Mangi, R., Sabetta, J., Lyons, R.W. 1995. Analysis of 110 series enterococcal infections. Med., 74: 191-200.

Ruoff, L., Lorena, D.E., L.A.M., Margaret, J., Jean, D., Spargo, Mary, J.F., Kathryn. 1990. Species Identities of Enterococci Isolated from Clinical Specimens. J. Clin. Microbiol., 28: 435-437.

Schleifer, K.H., R. Kilpper-Ba“lz. 1984. Transfer of Streptococcus faecalis and Streptococcus faecium to the genus Enterococcus nom. rev. as
Enterococcus faecalis comb. nov. and Enterococcus faecium comb. nov. Int. J. Syst. Bacteriol., 4: 31-34.

Schleifer, K.H., R. Kilpper-Ba“lz. 1987. Molecular and chemotaxonomic approaches to the classification of streptococci, enterococci and lactococci: a review. Syst. Appl. Microbiol., 10: 1-19.

Shankar, N., Lockatell, C.V., Baghdayan, A.S., Drachenberg, C., Gilmore, M.S., Johnson, D.E. 2001. Role of Enterococcus faecalis surface protein Esp in the pathogenesis of ascending urinary tract infection. Infect. Immun., 69: 4366-4372

Shankar, V., Baghdayan, A.S., Huycke, M.M., Lindahl, G., Gilmore, M.S. 1999. Infection-derived Enterococcus faecalis strains are enriched in esp, a gene encoding a novel surface protein. Infect. Immun., 67: 193-200.

Tyrrell, G.J., Turnbull, L., Teixeira, L.M., Lefebvre, J., Carvalho Mda, G., Facklam, R.R., Lovgren, M. 2002. Enterococcus gilvus sp. nov. and Enterococcus pallens sp. nov. isolated from human clinical specimens. $J$. Clin. Microbiol., 40: 1140-5.

Winn, W., Allen, S., Janda, W., et al. 2006. Charts. In : Koneman's Color Atlas and Text Book of Diagnostic Microbiology,6th Edition, Philadelphia USA:Lippincott Williams and Wilkins, 1442-1535.

\section{How to cite this article:}

Sumathi, B.G., Mohd. Shaffiulla and Kumarswamy. 2016. Post Operative Enterococci Infection from Cancer Patients in a Regional Cancer Centre, South India. Int.J.Curr.Microbiol.App.Sci. 5(8): 93-99. doi: http://dx.doi.org/10.20546/ijcmas.2016.508.012 